\title{
A Cegueira Pandêmica Saramaguiana como Metáfora de Época
}

\author{
Alex Villas Boas \\ Universidade Católica Portuguesa (UCP)
}

\section{Resumo}

O objetivo deste artigo é oferecer categorias que ajudem a refletir o evento pandemia em seu impacto cultural, que inaugura um tempo de busca de revisão de mentalidade, face às fragilidades que se desvelam na ocasião. Neste sentido, o evento pandêmico pode ser ligo à luz do romance Ensaio sobre a Cegueira de 1995, do escritor português José Saramago, desde uma perspectiva lacaniana sobre o papel do imaginário no desafio cultural de integração da alteridade. Tanto o romance português como o referencial lacaniano de alteridade tem sido objeto de hermenêuticas teológicas que indicam seu potencial de elucidação teórica do momento histórico que se vive no Ocidente, em que a alteridade se apresenta como um desafio dos novos tempos. Neste sentido, o evento pandemia se apresenta também como alteridade radical que desvela a real condição em que se encontra a sociedade e cultura contemporânea.

Palavras-chave: José Saramago, Jacques Lacan, Teologia e Literatura, Literatura Portuguesa.

\section{The Saramaguian Pandemic Blindness as Time Metaphor}

\begin{abstract}
The aim of this paper is to offer categories that help to reflect the pandemic event in its cultural impact, which inaugurates a time to search for understanding and a mentality review, in the face of the weaknesses that are unveiled at the time. In this sense, the pandemic event can be linked in the light of the 1995's novel Ensaio sobre a Cegueira, by the Portuguese writer José Saramago, from a Lacanian perspective on the role of the imaginary in the cultural challenge of integrating alterity. Both the Portuguese novel and the Lacanian reference of alterity have been the object of theological hermeneutics that indicate their potential for theoretical elucidation of the historical moment in the West, when alterity presents itself as a challenge of the new times, including religion. In this sense, the pandemic event also presents itself as a radical alterity that reveals the real condition in which contemporary society and culture finds itself.

Keywords: José Saramago, Jacques Lacan, Theology and Literature, Portuguese Literature.
\end{abstract}




\section{La ceguera pandémica saramaguiana como metáfora de época}

\section{Resumen}

El propósito de este artículo es ofrecer categorías que ayuden a reflejar el evento pandémico en su impacto cultural, lo que inaugura un tiempo para buscar una revisión de la mentalidad, ante las debilidades que se develan en su momento. En este sentido, el evento pandémico puede vincularse a la luz de la novela Ensaio sobre a Cegueira de 1995, del escritor portugués José Saramago, desde una perspectiva lacaniana sobre el papel del imaginario en el desafío cultural de integrar la alteridad. Tanto la novela portuguesa como la referencia lacaniana de la alteridad han sido objeto de hermenéuticas teológicas que señalan su potencial de elucidación teórica del momento histórico en Occidente, cuando la alteridad se presenta como un desafío de los nuevos tiempos. En este sentido, el evento pandémico también se presenta como una alteridad radical que revela la condición real en la que se encuentra la sociedad y la cultura contemporáneas. Palabras clave: José Saramago, Jacques Lacan, Teología y Literatura, Literatura portuguesa

\section{Introdução}

Na primeira metade do século XX, após as duas Grandes Guerras se impõe no cenário mundial o problema da recessão econômica, e como ele retroalimentava a tentação de três espíritos promovidos por grupos politicamente oportunistas que faziam uso da estratégia de expansão cultural de suas ideias para oferecer soluções populistas, a saber o fascismo que continuava vivo alimentando um espírito sectário e de revanche nacionalista, o espírito comunista que alimentava um conflito de classes, e espírito imperialista que alimentava um individualismo cultural para advogar uma liberdade mais radical do mercado, todas as opções marcadas por um traço potencialmente violento, e com modos próprios e sofisticados de camuflar suas retóricas de intolerância. Se impunha, assim, o desafio intelectual de enfrentar tais mentalidades que continuavam a ser alimentadas pelas feridas vivas e duradouras que uma guerra provoca, fonte de círculo vicioso de desejo de vingança que precisa ser interrompido. Grandes intelectuais europeus da segunda metade do século XX, conheciam esse mecanismo não somente dos debates acadêmicos, mas na própria biografia, tendo um bom número iniciado suas vidas acadêmicas após a Primeira Grande Guerra (1914-1918) e vivenciado o que até então eram histórias amargas do velho continente na Segunda Grande Guerra (1941-1945).

O sociólogo polonês Zygmunt Bauman (1925 - 2017) na obra intitulada Modernidade e Holocausto, ganhadora do Prêmio Europeu Amalfi para 
Sociologia e Ciências Sociais de 1989, identifica no palco europeu dos dois inauditos episódios bélicos uma correlação, não somente entre os eventos, mas precisamente uma relação direta entre modernidade e holocausto, de modo que este não seria um produto isolado da Alemanha nazista, mas um modo de ser da modernidade, e esta relação passa pela ideia de totalidade inerente a "solução" de exterminar a alteridade que se tornou um problema. Bauman extrai um modus operandi da modernidade presente no processo de execução de judeus em um campo de concentração nazista. A execução é designada por uma instância superior, um general que estabelece várias ordens, e cada comando será executado por um único soldado, de modo a cumprir seu dever ético na execução exclusiva da ordem que lhe foi dada. Assim, um soldado é encarregado exclusivamente de colocar os judeus de determinado alojamento dentro de um caminhão; outro é responsável por transportá-los de pavilhão; outro é responsável por prepara-los para um suposto banho, chegando inclusive a entregar sabonete e toalha; e outro tem a ordem de apertar um botão vermelho, em determinado horário em uma sala ao lado, sem a necessidade de ter ciência da finalidade do que deve executar. Por fim, só um último grupo de soldados tem a ordem de recolher os corpos, entretanto, sem saber a razão pelas quais tais pessoas foram executadas. Logo, cada um cumprindo seu papel realiza eticamente seu dever sem se dar conta que todos colaboram com a produção de vítimas invisíveis (BAUMAN, 1989, p. 197-229).

A Modernidade produzia um tipo de subjetividade que era capaz de eliminar a dignidade da alteridade em nome da obediência a um governo legitimamente eleito, um câncer na tradição humanista cristã moderna e na tradição política democrática, ambas na origem da história europeia, que apesar de ser o palco onde se desvelou as contradições da Modernidade, também iriam se identificar outros episódios de violência nacional e intolerância nos regimes ditatoriais do Hemisfério Sul, nos genocídios do Leste Europeu, e ainda com reminiscências no Oriente Médio. Se impunha o desafio de pensar um modo que freasse culturalmente as mentalidades que se mostravam na história recente serem potencialmente violentas, de onde emerge a categoria da alteridade. A proposta deste trabalho é refletir sobre a noção de alteridade a partir do papel da linguagem na constituição da subjetividade, a saber Jacques Lacan (1901-1981) e José Saramago (19222010), bem como possíveis hermenêuticas teológicas da questão. 


\section{Subjetividade e Linguagem em Jacques Lacan}

Jacques Lacan (1901 - 1981) entende ser o desejo a categoria fundamental para uma teoria do sujeito. Em seu retorno à Frend, visa sobretudo, uma teoria da consciência como constitutiva do sujeito, e revisita criticamente a originalidade freudiana, tentando sanar o déficit filosófico do psicanalista vienense, e elabora sua hipótese fundamental de que o "inconsciente é estruturado como linguagem”, a começar da observação clínica da psicanálise de distinguir significantes e significados, , contudo com a "primazia do significante sobre o significado" (LACAN, 1956, p. 461), sendo tarefa da compreensão do profundo a análise do significante, que se apresenta como enigma, em meio a afirmações confusas e aparentemente sem sentido. Ao adotar uma nova postura epistemológica que faz uso da concepção de estrutura linguística visa então encontrar uma ordem análoga dos elementos significantes da linguagem nos elementos significantes do insconsciente, como modo de compreender a formação da consciência do sujeito, entendida como um idioma pessoal.

Em sua tese em psiquiatria Da Psicose paranóica e suas relações com a personalidade (1932), dá importância metodológica à psicose para gênese do eu como um surgimento, ou seja, a "formação" do eu é um "novo ato psíquico", que coincide com o que o pai da psicanálise chamou de narcisismo. Este é descrito pelo mesmo na obra Introdução ao Narcisismo, e visa explicar os fenômenos do adoecimento, apaixonamento e psicose. O narcisismo então é um novo ato psíquico em que o "eu" surge entre o "autoerotismo" e o "amor de objeto", ou seja, entre o momento em que pulsões procuram suas realizações de modo errático e não convergente, mas sim no momento em que seleciona seus objetos de realização, especialmente o objeto de amor. Ocorre então, uma passagem entre o "eu ideal" [Ideal Ich] e o "ideal do eu" [Ich Ideal]. A criança nasce nessa condição de "ideal do eu", que é a recuperação do próprio narcisismo dos pais e familiares, enquanto sonhos e expectativas não realizadas, que Freud chama de narcisismo primário, e no qual é lançado o recém-nascido. Assim, na formação [Bildung] do eu, a imagem [Bild] tem uma função importante na história, entre o "ideal do eu" e o "eu ideal” (1953/54, p. 10-37). Daí a referência ao Narciso, de Ovídio (43aC $17 / 18 \mathrm{dC})$ em sua obra Metamorfoses.

Lacan verá nisso que há algo na imagem que é capaz de transformar, ou ainda, libertar o eu, contudo, entende que Freud não explica como essas duas instâncias psíquicas se formam, deixando em aberto o problema da 
formação do eu e sua articulação com a formação do sujeito. Partindo então de uma leitura crítica de personalidade identifica três parâmetros, que são três exigências para a noção de sujeito: 1) Função de Síntese; 2) Desenvolvimento biográfico; 3) Tensão nas relações sociais. Exigências essas das quais se desenvolve três atributos da personalidade imaginária, sintese, intencionalidade e responsabilidade ou consciência ética. Tendo Lacan transportado da epistemologia a ideia de sujeito, a função de sintese está relacionada historicamente a função de conhecimento, no qual a síntese está associada a tarefa de reunir a diversidade em uma identidade, pensar do múltiplo ao uno. É a elaboração de sínteses que possibilita a subjetividade perceber as coisas em um todo, e com isso a apreensão do real. Contudo, a síntese do sujeito é sempre parcial, é a perspectiva de um único ângulo. Essa parcialdade fica mais evidente no desenvolvimento biográfico, no qual o sujeito mesmo toma consciência de que ao contar sua história, toda narrativa é parcial ao mesmo sujeito que a relê, transforma e reconta a própria biografia, em um progresso dialético dos "ideais de si mesmo". A cada momento que assim procede transforma a síntese que havia feito, e com isso vai reeditando a intencionalidade, ou seja, a noção de sentido, que é indissociável ao processo de produção de subjetividade (DUNKER, 1996, p. 2-10).

Com isso, se afirma que subjetividade é sentido e a pergunta pelo sentido é, no fundo, a pergunta pelo sujeito, pois o sujeito será visto como objeto do sentido interno e, portanto, um fenômeno que comporta sua intencionalidade em sua tarefa de se autogerar (PRADO JR, 1998, p. 205; 1991, p. 22; FELIPPI, 1998 , p. 25). Esses dois conceitos se articulam na função de síntese como uma relação de pensamento e intencionalidade, ou ainda, vontade.

Há ainda uma nova relativização dessa síntese na tensão das relações sociais, uma tensão intersubjetiva, ou seja, há o olhar do outro sobre o sujeito que põe em cheque essa síntese narcísica entre o "ideal do eu" e o "eu ideal", em que o sujeito não consegue mais se reconhecer no seu ideal, como uma espécie de alienação, uma patologia do reconhecimento. Quando essa tensão não consegue integrar o olhar do outro e a imagem que este apresenta sobre "mim mesmo", ocorre a psicose construindo seu próprio "sistema de mundo" dentro de uma "inércia egóica" provocando uma falha na função de síntese (LACAN, 1953/54, p. 126; 1955/56, p. 20).

Ocorre assim, no desenvolvimento biográfico uma patologia da sintese provocada pelo olhar do outro, mas que ao mesmo tempo solicita uma saída do sujeito de um processo psicótico, que enclausura o sujeito em seu 
mundo. Lacan extrai um termo de um poema de sua autoria a uma revista surrealista, movimento que se aproximou, ao se tornar médico pessoal de Picasso, a saber Hiatus Irrationatis (LACAN, 1933). Deste modo, há hiatos no desenvolvimento biográfico que atuam como uma "ilusão de memória", em que ocorre um lembrar errado, ou lembrar de uma coisa que não aconteceu, o que provoca uma história surreal no desenvolvimento biográfico, um paralogismo situado em um sistema de mundo próprio que resulta em uma confusão entre o imaginário e o real.

O hiato é uma perturbação na função de síntese, que por sua vez interfere na capacidade de apreender o real, um fenômeno elementar que vai debilitando a personalidade, ou seja, adoecendo a alma, enquanto vitalidade interior, o que solicita uma atitude. Nesse sentido, a relação social com o outro nunca é acessada diretamente no real, mas em sua relação com o simbólico e o imaginário, de modo que a relação de alteridade está função da relação consigo mesmo, com os próprios ideais. O outro é a instância primeira da realidade que solicita do sujeito novas sínteses da realidade, ou dito de outro modo, o outro solicita da subjetivação o desenvolvimento da responsabilidade, como ampliação e integração do real, do simbólico e do imaginário, espaço que constitui a estrutura social.

Nesse sentido, a tensão social, enquanto manifestação da estrutura social, é o espaço onde os atos do sujeito ganham valores intersubjetivos como atos de uma personalidade que é responsável. A responsabilidade é especialmente convocada no processo de subjetivação diante da angústia que aparece como expressão de um hiato biográfico, perturbação de síntese e tensão social intersubjetiva. A responsabilidade tem a função de integrar o real, o simbólico e o imaginário, enquanto totalidade social, no movimento do universal ao particular, ou seja, enquanto processo mesmo de criação da identidade (LACAN, 1932, p. 248).

A leitura do narcisismo freudiano na teoria lacaniana aponta para a questão de que o acesso ao real só é possível por uma imagem da realidade, que tem a ver com a imagem que o sujeito tem de si e do outro em constante solicitação de reelaboração. Essa imagem só é possível pela linguagem que Lacan chama de Outro ou a Ordem simbólica que integra todo o Sistema simbólico e que abarca toda a realidade material, imaterial e histórica. Nesse Outro se encontra o eu ideal que é constituído pelos ideais do Outro, que é composto pelos ideais não realizados e ditos dos pais e familiares [narcisismo primário], e reforçado pelas expectativas que a sociedade também lança sobre 
o indivíduo [narcisismo secundário]. Tais ideais de outros formam uma cadeia de significantes, ou seja, imagens representativas das expectativas de outros reunidas no Outro, enquanto ordem simbólica. Essa ordem simbólica se estrutura como linguagem e se relaciona com o inconsciente do sujeito, que por sua vez é estruturado como linguagem.

O sujeito em si é vazio, e se desloca na cadeia de significantes do Outro, dos quais alguns são determinantes para a formação da identidade, contudo, ainda enquanto representação imagética do Outro, em termos lacanianos constitui uma alienação. Dito de outro modo, o sujeito ainda se identifica com a projeção das imagens de outros sobre si, que se estabelece como uma heteronomia radical (LACAN, 1955/56, p. 307).

A produção de subjetividade na teoria lacanina supõe obrigatoriamente uma alteridade complexa, no qual o Outro do discurso do inconsciente jamais está ausente na relação do sujeito com o outro, seu semelhante, contudo, sob a tarefa de desalienação dessa heteronomia radical, que se manifesta sobretudo na tensão social e seu principal sintoma, a angústia, quando o outro não coincide exatamente com o Outro. O real em Lacan, inclusive o real do outro, coincide com o histórico e é aquilo que não está inscrito no simbólico, que por sua vez se dá a conhecer como sintoma. O real, portanto, se manifesta como algo da história que não está integrado na linguagem, enquanto desenvolvimento biográfico que é a condição de relação com o outro, o que exige uma transformação no imaginário. O hiato biográfico produz esse sentimento de estranheza que solicita a transformação da imagem, como símbolo do eu, e do outro integrado na Ordem Simbólica, como um outro eu.

Deste modo, a criação da identidade, de um eu que se vê em uma imagem, passa pela tarefa subjetiva de transformar essa imagem de acordo com a necessidade de integração na ordem simbólica. O processo de produção de subjetividade por meio da desalienação dos significantes do Outro se dá por uma dinâmica de negatividade, ou seja, vai identificando o que não é autenticamente seu, na cadeia de significantes, ou seja, o sujeito não é aquilo que o Outro diz dele, mas aquilo que decide ser, a começar pelo que não deseja ser (LACAN, 1957/58, p. 537-590).

A tensão social provoca esse processo de negatividade que gera um bloqueio de síntese, um momento da personalidade que ela não captura o real. Esse momento que se impõe como divisão da unidade, supõe na teoria do sujeito lacaniana uma teoria do tempo, em que a identidade é um resultado de um processo de identificação e a coroação desse processo com um ato 
de conclusão no tempo, enquanto consciência possível daquele momento histórico, solicitado pelo real manifesto na tensão intersubjetiva. Inicia-se assim, um tempo de busca de compreensão em que a referência do imaginário ao eu é temporalizada mudança de um momento de concluir para um tempo de compreender, em que se faz necessário a simbolização dos conteúdos não narrados, porém presentes na história, ou seja, no real, e que por isso atuam como ponto cego, atuam como "fantasmas", isto é, concepções sintomáticas das representações imaginárias (ARAUJO; BAPTISTA, 2003, p. 171-172).

Ademais, a noção de imaginário lacaniana incorpora a estrutura da razão de Émile Meyerson, de seu trabalho chamado Identidade e Realidade (1908). Aqui o autor trabalha com a razão como sendo uma expectativa de regularidade que se concretiza em diversas formas de criar repetições, analogias, simetrias, comparações, de modo que pensar é identificar e correlacionar. Há um privilégio da identificação que para cada ponto da realidade se correlaciona com um ponto de representação, e tal relação produz um imaginário, que se pretende cada vez mais consistente, produzindo uma correlação de identificação e antecipação ou busca de previsibilidade dessa representação com o identificado. Isso em Lacan resultou que onde há imaginário há antecipação, procurando ver o sentido onde não está, uma espécie de busca de ajuste de forma, que visa atender a expectativa de correlação. Há com isso a produção de um insight que se antecipa, capaz de pensar por identificação, de modo a trabalhar com ausência, produzindo uma presença. Esse processo de agir produzindo uma representação da presença é o que se chama de imaginário, e a transformação da identidade é um processo de identificação com uma imagem.

Também se saliente a identificação do sujeito na abordagem psicanalítica não se é como a análise de um objeto de conhecimento, dada a dinamicidade de sua dimensão de tempo e sua tarefa de negatividade ligada aos momentos de tensão social, que se lhe escapa o controle do eu, mas sim o sujeito tem uma demanda de reconhecimento, no qual se lhe é solicitado o reconhecimento de si e do outro, como sendo um igual ao outro. A identificação, portanto, é a transformação que acontece no sujeito toda vez que ele assume uma imagem, que estabelece uma relação fundamental entre simbólico e imaginário, toda vez que o en mesmo [self] reconhece uma imagem, ele se transformou em outra coisa.

Todavia, a teoria lacaniana do tempo, enquanto parte da teoria do sujeito, ao enfatizar que a transformação acontece no tempo, como toda 
transformação deixa um resíduo da operação. Esse resíduo é uma "não apreensão total" da imagem, pois o reconhecimento do sujeito é no fundo o reconhecimento do desejo que sendo inesgotável, nunca apreende a totalidade da identidade do objeto, que é parcial, ou seja, se dá no tempo. O resíduo de operação é uma "falta" que impede o objeto do desejo de se tornar empírico, o que seria, por sua vez, uma dinâmica psicótica, na medida em o desejo julga encontrar uma prova de satisfação total em algum objeto, que provocaria a fixação. Esse resíduo é, portanto, o núcleo irracional do desejo, nunca satisfeito.

O sujeito, apesar da demanda de um saber sobre si mesmo, que no momento em que logra escutar a si mesmo e ouvir, em vez de palavras vãs, algo que faça sentido. Esse sentido nunca é total, o que produz o desenfreamento significante, enquanto movimento que procura ver o sentido onde não está, procurando atender a dinâmica da insaciabilidade do desejo (LACAN, 1958/59, p. 13s). Essas três dimensões estruturam a subjetividade: o desejo, a linguagem e o inconsciente, e é a intrincação delas que aparece como uma das conclusões fundamentais para a hipótese do inconsciente estruturado como linguagem.

Entendido o inconsciente como linguagem é o processo metafórico o "produtor de sentido" situada no ponto preciso onde o "sentido" se produz no "não sentido" [non-sense], e assim, dá suporte a cadeia de significantes que em seu caráter primordial governa o sujeito. O processo metafórico é corroborado pelo processo metonímico que vai produzindo transferência de denominação onde a função reside na conexão de um significante novo a um significante antigo, em relação de contiguidade e que o substitui, o que indica que o procedimento metonímico é o próprio processo do desejo. Diz Lacan que é na substituição de significante a significante que se produz o efeito de significação que é de poesia ou criação, em outras palavras, o advento da significação em questão (LACAN, 1956, p. 515).

Para Lacan, os processos metafóricos e metonímicos é que regulam o funcionamento inconsciente, em que a metáfora funciona como substituição significante e a metonímia como combinação entre significantes.

Deste modo, o simbólico lacaniano não é uma totalidade, pois isso faria com o que o sujeito viva procurando um Outro em que possa se ancorar, lhe oferençendo amor e segurança, que na prática incorreria na mera substituição de algo que ocupe o lugar do Outro, a ser eregido como razão de sua existência, ou seja, uma dependência que impede a produção 
da subjetividade de concluir a identidade do indivíduo. Essa dependência é distinta da demanda do amor que é construída, como um outro, circunscrito pela imagem de ordem simbólica sim, porém da ordem do real, que ajuda a lidar com a falta constitutiva do indivíduo, ou seja, com a construção da sua identidade.

Pensando a partir da psicocrítica lacaniana, Slavoj Žižek levanta a questão do fascinio do totalitarismo, à partir das incidências políticas do real lacaniano, que não é uma essência última que sustenta a realidade, enquanto sistema compartilhado de discursos, trocas, relações que estruturam os laços sociais, o que inclui uma ilusão compartilhada que estrutura as relações, de modo que totalitarismo, enquanto ilusão, não deixa de ser um imaginário, porém não tem a ver com uma perturbação da realidade, mas como um retorno no real, dentro de um fenômeno da foraclusão da psicose. A foraclusão foi o termo que Lacan utilizou para traduzir a expressão alemã Verwerfung utilizada por Freud para indicar rejeição, ao passo que o termo utilizado por Lacan é retirado do campo jurídico, que pode ser entendido como prescrição simbólica de um direito. Assim, os significantes foracluídos ou prescritos, diferente do que ocorre no recalque, de serem integrados ao consciente via simbólico, retornam de fora pela via do real, como um fenômeno alucinatório, como aquilo que resiste à simbolização, que não tem palavra, que não tem nome, se expressa por meio da angústia, não inscrito no simbólico, mas retorna ao real, saindo da metáfora sintomática, e remetendo o caminho que foi negado, como uma solução delirante que confere um paralogismo, ou seja, uma lógica interna não partilhada por toda a sociedade, mas compartilhada por um grupo que retroalimenta percepção paranoica como ordem simbólica alternativa.

Nesse sentido o fascínio do totalitarismo em suas formas históricas, quer de direita, quer de esquerda, não são formações completamente exteriores aos nossos dispositivos tidos como democráticos, em seus diversas formas, pois todas estão organizadas em torno de um equívoco básico, a saber a elevação de fantasias particulares a condição de um falso universal, ou seja, uma confusão neurótica que cria unidade como um Outro completo, de que todas as demandas do desejo podem ser realizadas e em cima desta ilusão neurótica que sustenta as ideologias particulares como fantasia social.

Desse problema de imaginário base, se sustentam as demais ilusões, no qual Žižek vê o nazismo e o fascismo como processos psicóticos elaborados como retorno continuado de algo que não se inscreveu no simbólico, mas cria um simbólico paranoico, ao passo que o totalitarismo stalinista segue um 
processo fetichista. Tal qual incide dividindo a posição do percebido, uma negação metonímica, no qual a parte substitui o todo, mas sem contradição, ou seja, dentro de uma lógica de perversão que a contradição que não consegue ser posta, opera essa divisão, e instrumentaliza essa divisão sobre o outro. Assim, o totalitarismo de esquerda acontece em cima de uma noção de partido (a parte pelo todo) como sintoma de uma fetichização do partido, no qual a contradição não consegue ser vista. Em ambas as formas de totalitarismo há uma fantasia neurótica, a criação de um mestre que cada um inventa para obedecer, transferindo a própria liberdade para o outro no ato de obedecer, formando o Um gerado pela exclusão radical do outro. O efeito nefasto dessa neurose da era do ego que chega a contemporaneidade é a produção de um novo sintoma social que é o cinismo, dentro de um imaginário de alguma forma de totalitarismo que "desobriga a pensar ou impede de pensar ativamente” (ŽIIŽEK, 2013, p. posição 119) ${ }^{1}$.

Tal cinismo é sustentado, segundo a análise política de corte lacaniano de Žižek, pela mudança na função do supereu, que não é mais interditor, mas rege uma economia do gozo, um "imperativo da jonissance" (ŽIŽEK, 2011, p. 343) continuamente interessado em renovar suas estratégias de gozo, gerando subjetividades compulsórias, e ao mesmo tempo como patologias sociais que levam a indiferença do olhar em relação ao outro.

\section{A cegueira saramaguiana como metáfora de época}

Comparada a narrativa de Michel Foucault sobre Maio de 68, de uma mobilização cultural ou de uma nova imaginação política (SAVATER, 2015) ou da "revolução simbólica" de Michel de Certeau, como "revolução fundadora" do "risco de existir", que inauguraria o apelo a uma possível transição do presente com seu passado, não sem conviver com uma perspectiva oriunda do passado com seu presente, reticente a transição, até o ponto em que este passado atingisse sua estranheza mais radical e integrasse o novo (FABRE, 2018), a perspectiva de Saramago de Maio de 68 é a de que "não mudou coisa nenhuma". Para o Escritor português, em entrevista dada em 1999 é que muitos "[d']os universitários de ontem que buscavam a mudança estrutural do mundo" tornaram-se "executivos, professores e políticos" que "usufruem da sociedade de consumo" (SARAMAGO apud FRANCO, 2011, p. 747). A tensão contra a cultura repressora, se deslocou para a tensão entre movimento emancipatório e ofertas aliciantes da sociedade de consumo.

Citação segue padrão da Edição Digital Kindle, feita em “posições”(= p). 
Em 12 de novembro de 2005, a RTP, Rádio e Televisão de Portugal veiculava a opinião de José Saramago à respeito de Maio de 68, em um lançamento sobre as Intermitências da Morte: "os protestos do Maio de 68 em Paris acabarão por parecer insignificantes face à gravidade que podem vir a atingir as manifestações dos que se sentem excluídos" e ainda específica, "dos que vivem à margem, sobretudo "nas periferias das grandes cidades". Contudo ao contrário do pensée anti-68, como diz Serge Audier (2008), das narrativas que negam a importância de Maio de 68, e que se opuseram inclusive a instituição de uma data comemorativa, Saramago parece mais apontar para uma tarefa a se realizar, em que "é preciso retificar a situação dos "excluídos" na Europa" (RTP, 2005), que vê em Maio de 68, a consolidação de um pensamento solidário aos que mais sofrem, mas com um obstáculo ainda a ser superado, para além das estruturas sociais. Dito de outro modo, há uma tarefa cultural em aberto para além das conquistas políticas, sendo estas vulneráveis as mentalidades que não se apropriam da necessidade das mudanças.

Saramago, assim como outros intelectuais que dividiram o mesmo processo histórico de crise da Modernidade, não eram arredios as necessárias mudanças, mas sim ao mecanismos de cegueira que atuavam como ponto cego, quer sejam nos discursos românticos de transformação quer seja nos discursos oportunistas que visavam ser alimentados pelos fantasmas modernos, dentro de um substrato cultural de romantismos e idealismos. Essa substrato cultural de idealização como "mal uso da abstração" também acaba por hipostasear "macroentidades" (LEVY, 2011, p. 12-14) que se tornam objeto dessa míope abstração como a Economia, a Filosofia, a Teologia, a Religião, a Igreja, a Ciência, a Esquerda, a Direita, e assim por diante, dessa maneira acaba por não se considerar os agentes efetivos que operacionalizam tais macroentidades, que são indivíduos estruturalmente situados (WELTER, 2003, p. 26), como ser contextual, sujeito ao tempo e a própria história, bem como em situação de relação com outrem, de onde resulta a complexidade e ambiguidade que se desvela em seus inúmeros espaços, existencialmente sincrônico a dinâmica de bons cidadãos e portadores de valores indubitáveis, como pessoas vulneráveis às paixões, ao poder, à ganância, e vice versa e adversamente proporcional à qualquer afirmação absoluta porque situado em processos históricos, de modo que o ser humano em sua ambiguidade constitutiva é e não é, sem deixar de ser o que é, habita em um não-lugar social contemporâneo, que constantemente é interpelado a colocar em questão suas certezas. 
Tal imaginário que alimenta formas ideais de moldura de pensamento se constituem como uma "patologia do saber", uma "inteligência cega":

A antiga patologia do pensamento dava uma vida independente aos mitos e aos deuses que criava. A patologia moderna do espírito está na hipersimplificação que a torna cega peranta a complexidade do real. A patologia da ideia está no idealismo, onde a ideia oculta a realidade que se encarrega de traduzir e se considera como a única real. A doença da teoria está no doutrinarismo e no dogmatismo, que fecham a teoria sobre ela própria e a petrificam. A patologia da razão é a racionalização que encerra o real num sistema de ideias coerente, mas parcial e unilateral, e que não sabe nem que uma parte do real é irracionalizável, nem que a racionalidade se encarrega de dialogar com o irracionalizável (MORIN, 1990, p. 22-23).

Ademais, tal estrutura simbólica idealista ocupa o lugar de um Outro absoluto, para pensar em Lacan, que retroalimenta uma subjetividade narcísista que se instala entre o medo e a indiferença, como define Bauman e Donskis resultado da perda de sensibilidade em relação a outrem, e por isso mesmo bastante adequada para uma lógica de mercado, que conta com essa inteligência cega, incapaz de reconhecer os processos que produzem vítimas invisíveis, mas extremante hábil em encontrar razões esclarecedoras para a situação das mesmas:

O mal em nossos dias é em geral identificado a migrantes e muçulmanos, e com frequencia a intelectuais e políticos de esquerda, os quais por sua vez, associam o mal a ideias conservadoras e liberais. Mas todos são superados pelos que conseguem reunir e situar todo mal do mundo no projeto da modernidade e no liberalismo com ela confundido. Daí aguardamos o ataque de bárbaros e inimigos da liberdade vindos de fora de nossos portões; novas guerras frias e quentes e ataques de mísseis de Estados pertencentes ao "eixo do mal", enquanto somos mortos silenciosa e eficazmente por nossa tecnocracia $[\ldots]$ uma economia racionalmente inexplicável, a que foram subordinadas todas as formas de política e de Estado. [...] Há um declínio totalmente banal, discreto, implausível, que ocorre no âmbito privado - para pessoas treinadas pelas fantasias e pela estética hollywoodianas, é difícil acreditar que uma época e suas esperanças estejam desaparecendo diante de seus olhos. E por que não há lamento nem dor? Porque a economia tem exatamente a mesma lógica da força e da dominação. Ela apenas se mudou do front para a distribuição no mercado. Claro, é melhor escolher formas pacíficas de poder (BAUMAN; DONSKINS, 2013, p. 202). 
No romance Ensaio sobre a cegueira, vencedor do Prêmio Camões e Prêmio Nobel de Literatura de José Saramago, a razão de tais reticências em relação a mudança de mentalidade pode ser encontrada no fenômeno da falta de percepção visual saramaguiana não é devido à ausência de luz, e sim, claridão, excesso de luz:

Chegara mesmo ao ponto de pensar que a escuridão em que os cegos viviam não era, afinal, senão a simples ausência da luz, que o que chamamos cegueira era algo que se limitava a cobrir a aparência dos seres e das coisas, deixando-os intactos por trás do seu véu negro. Agora, pelo contrário, ei-lo que se encontrava mergulhado uma brancura tão luminosa, tão total, que devorava, mais do que absorvia, não só as cores, mas as próprias coisas e seres, tornando-os, por essa maneira, duplamente invisíveis (SARAMAGO, 1995, p. 15-26).

Tal cegueira por excesso de luz, poderia ser entendida como um excesso de certeza unilateral, como desconhecimento dos irracionalizáveis mecanismos psicodinâmicos, e reproduzíveis ao mesmo tempo em sóciodinâmicas, uma cegueira em relação ao outro, provando um déficit psicológico e sociológico na compreensão do tecido cultural. Essa desconstrução da situação de alteridade é seguida da desconstrução da situação temporal.

Na cegueira saramaguiana, há a desconstrução do "lugar antropológico" da subjetividade moderna, um destronamento do ego ao se desvelar sua condição de transitoriedade das referências espaço temporais e axiológicas que confere à cultura e ao indivíduo uma identidade. Ocorre uma espécie de antropologia negativa que vai despindo os fatores situacionais, em busca de um modo de ser humano “em si”. Assim, não há marcas usuais de historicidade, limitando-se a consciência dos personagens em "antes da cegueira", bem como estes se encontram no anonimato, sendo tratados apenas por rótulos como o médico, a criança, a rapariga, o policial, e assim com todos os personagens. O holofote narrativo será direcionado, primeiramente, para a encarnação dos valores absolutos em um indivíduo, de modo especial o valor do self moderno, um oftalmologista, herdeiro das luzes, racionalmente esclarecido, ético, democrático, uma líderança que deve conduzir a sociedade em trevas ao esclarecimento, cartesianamente convicto de que seu cogito era o único fundamento seguro para reconduzir à sociedade à luz, que já era na verdade, demasiada. 
Enquanto protótipo do sujeito advindo da modernidade, o médico aparentemente funda as bases da Sociedade na figura da família, mas sua ética e seus valores democráticos não são suficientemente "iluminadores" para superar a cegueira que a todos atingia. A insuficiência das proposições iluminadoras do oftalmologista cego que apontava "o que devíamos fazer", "como eu entendo" por se apresentar como "gente honesta", era demasiada inadequada para os que já tinham perdido a fé na autossuficiência cega de seus líderes, face a constatação mais realista da dor da história: "o que somos de verdade aqui, é pessoas com fome” (SARAMAGO, 1995, p. 103).

Tal autossuficiência no romance saramaguiano tem sua expressão institucional na forma do Governo que se comunica à distância da realidade do povo, na "voz do altifalante" [sic], voz que não tem ouvidos e que está distante da complexidade da realidade, em que "as expectativas do Governo e as previsões da comunidade científica foram simplesmente por água abaixo":

As autoridades promoveram às pressas reuniões médicas, sobretudo de oftalmologistas e neurologistas. Por causa do tempo que fatalmente levaria a organizar, não se chegou a convocar o congresso que alguns preconizavam, mas em compensação não faltaram os colóquios, os seminários, as mesasredondas, uns abertos ao público, outros celebrados à porta-fechada. O efeito conjugado da patente inutilidade dos debates e os casos de algumas cegueiras súbitas ocorridas em meio das sessões, com o orador a gritar, Estou cego, estou cego, levaram os jornais, a rádio e a televisão, quase todos, a deixarem de ocupar-se de tais iniciativas [...] certos órgãos de comunicação que vivendo à custa de sensacionalismos de todo o tipo, das graças e das desgraças alheias, não estavam dispostos a perder nenhuma ocasião que aparecesse de relatar ao vivo, com a dramaticidade que a situação justificava, a cegueira súbita, por exemplo, de um catedrático de oftalmologia (SARAMAGO, 1995, p. 124).

A cegueira saramaguiana vai depondo essa subjetividade moderna, de qualquer forma de messianismo secular, especialmente do Governo, apresentada como "prova da progressiva deterioração do estado de espírito geral", que vai, cada vez mais confuso, progressivamente saindo de cena, e na mesma medida de sua ausência e silêncio, se instala o fenômeno da violência, outra forma de autossuficiência como monarquia do caos, que passa a explorar as vítimas, tendo o medo como plataforma política:

O da pistola continuou, Está dito e não há volta atrás, a partir de hoje seremos nós a governar a comida [...] A comida passa a ser vendida, quem quiser comer, paga (SARAMAGO, 1995, p. 140). 
Tal percurso da autossuficiência da subjetividade moderna à irrupção da violência, passa pela cegueira para a alteridade. Em tal cegueira, que se manifesta como desorganização social, se instala o oportunismo como ordem criminal paralela e parasita, que contamina ainda mais a cegueira, de uma não visão, para uma cegueira moral. A cegueira saramaguiana coincide com uma inteligência cega, como uma "patologia do saber" que estruturalmente não reconhece o outro e sua elaboração de realidade e ordem social, legitimamente instituída (sintoma da fragilidade democrática) ou não (organização criminal), mas hermeticamente solidificada pela certeza solipsista - "a ilusão da luz". No romance português, "a cegueira não era viver banalmente rodeado de trevas", pois isso ainda permitiria viver as apalpadelas da descoberta, mas se vive "no interior de uma gloriosa luminosidade". A cegueira desvela a radical condição humana em sua fragilidade despida, a sua vulnerabilidade constitutiva que se manifesta no fenômeno do medo, como o gérmen da barbárie presente antes da epidemia, como foram nomeada no romance, porém já com características pandêmicas: “já éramos cegos no momento em que cegámos, o medo nos cegou, o medo nos fará continuar cegos". Por esse mesmo motivo, não é suficiente sair da quarentena, pois a sociedade inteira participa dessa cegueira, de modo que o que acontecia no microcosmo da quarentena, aconteceu perenemente em todo macrocosmo da condição humana: "o mundo está todo aqui dentro" (SARAMAGO, 1995, p. 94; 101; 131).

Progressivamente, as ocasiões de fragilidade e necessidades que vão se agravando, vão deixando todos "entregues a nós mesmos" e vai se percebendo do que efetivamente é feito esse ser humano em movimento de desumanização de massa: "é desta massa que somos feitos, metade de indiferença e metade de ruindade" (SARAMAGO, 1995, p. 54; 40).

Tal subjetividade, lacanianamente narcísista, pode ser vista como peça chave da engrenagem de um sistema de crença. No último capítulo do romancista português, quando o pequeno grupo que saiu das camaratas chegam a uma Igreja Católica, lá encontra também o Cristo crucificado, bem como os demais santos, porém observa o autor que as imagens estão tapadas, porque elas "vêem com os olhos que as vêem" e, portanto, cegadas pelos cegos que lançam sua visão sobre eles, a crença não pode ajudar a elucidar a própria condição: "misericordiosos ou sofredores olhares não contemplavam mais que a própria cegueira”(SARAMAGO, 1995, p 302-303).

A única personagem na obra que enxerga é a mulher do médico, que mesmo enxergando, mantém seu anonimato e vive como se também 
fosse cega. A ela parece se dirigir a epígrafe do próprio livro, e com ela os leitores que querem ver: "Se podes olhar, vê. Se podes ver, repara". Nesse exercício de olhar mais profundamente, se desenvolve o crescimento da personagem, que se indigna com a exploração das mulheres, que assume a liderança da libertação do grupo, que sofre a raiva da injustiça, mas também consegue "amparar a fragilidade da vida um dia após outro dia" e desloca a questão para uma perspectiva mais profunda, a de que "não há cegos, mas cegueiras":

Por que foi que cegámos, Não sei, talvez um dia se chegue a conhecer a razão, Queres que te diga o que penso, Diz, Penso que não cegámos, penso que estamos cegos. Cegos que vêem, Cegos que, vendo, não vêem (SARAMAGO, 1995, p. 308-310; 283).

Em Ensaio sobre a Cegueira o autor emoldura o "não-lugar" da condição humana, marcada por sua transitoriedade e a necessidade de um constante refazer-se, na medida em que grandes valores da humanidade sob uma forma de absolutização histórica que acentua a processos de produção de subjetividade incapazes de abertura à alteridade, exclui sistematicamente (indivíduos, grupos, culturas...) da participação do outro na construção de um ethos. Deste modo, o embate com a realidade quando esta não condiz ou contrária a mentalidade do indivíduo ocidental moderno, emerge violenta e irracionalmente a dimensão do medo, espaço para oportunistas se apresentarem como corajosos heróis, que são aceitos de modo igualmente irracional, por simplesmente ocuparem o imaginário da oferta da segurança, ainda que ilusória.

No romance saramaguiano não há messias, e o "o pior cego foi aquele que não quis ver", esclarecido de suas certezas e cego para a realidade. O restabelecimento da visão passa por uma primazia de reconhecer solidariamente a dor da história e do diálogo como vias para o discernimento. Em termos jamesonianos, a cegueira é o sintoma de um insconciente político e cultural que não vê a dor da história como necessidades negadas (JAMESON, 1992, p. 36-37), e por isso não transcende da moral individual para uma consciência coletiva. Diz o escritor português: "Chega de filosofias e taumaturgias, demo-nos as mãos e vamos à vida", na boca da única personagem que podia ver. Nos tempos de obscurantismo do romance o autor sugere o imperativo e a crença no diálogo como meio privilegiado de construção de uma cultura contrahegemônica e discernimento das contradições culturais, pois foi observando os cegos que a personagem 
aprendeu que em tempos de cegueira: "só a voz e o ouvido tinham agora alguma utilidade" (SARAMAGO, 1995, p. 283; 289; 101-102).

O imaginário proposto por Saramago em seu romance parece ser convergente a necessidade de um imaginário que desperte e retroalimente processos de produção de subjetividade abertas à alteridade, tal qual pensados por Lacan, em que cegueira pandêmica se instala como alteridade radical inegável e impõe uma tensão social que desvela os sintomas da cegueira preexistente, a de não reconhecer o outro em sua comum dignidade no modo de pensar e organizar a sociedade. A pandemia inaugura um tempo de busca de compreensão, não somente das causas da doença física, mas das doenças culturais que já eram invisíveis, a saber a impossibilidade de se manter uma cultura de identidades hegemônicas que não reconhecem a comum dignidade das alteridades, com suas implicações culturais, política, econômicas e religiosas.

\section{Hermenêuticas teológicas da cegueira}

A relação entre subjetividade e sociedade, de modo particular o diagnóstico sócio-cultural recorte lacaniano da sociedade foi utilizado pelo teólogo metodista Jorg Rieger como instrumento de análise para o problema racional desde a perspectiva da black theology ou teologia da libertação norte americana ligada a opção pelos negros. Rieger retoma a percepção lacaniana de uma Era do Ego, a partir de um aforismo do psicanalista francês: "A mulher não existe" (LACAN, 1974, p. 559). Indicava de algum modo que "A" mulher idealizada ou como projeção do desejo inconsciente apreendida na moldura de objeto de um imaginário não corresponde à realidade das mulheres em sua complexidade e pluralidade, critérios esses de apreensão da realidade, inclusive. Tal expressão lacaniana foi lacaneanamente parafraseada pelo teólogo norteamericano como "o pobre não existe", como constatação de sua observação de como as políticas públicas do Norte eram insuficientes para com as demandas sociais, especialmente para a questão racial (RIEGER, 2009, p. 24). Acresce-se o fato de identificar como os mecanismos de idealização romântica da mulher, também podem ser deslocados para uma idealização dos pobres, ou de outras minorias que reinvidacam o seu reconhecimento que não corrobora para um diálogo social efetivo e que atenda a complexidade da realidade dos mesmos, pois, como não há "a" mulher, também não há "o" pobre, "o" negro, "o" migrante... mas sim mulheres, pobres, negros, migrantes, entre tantos outros grupos, que constituem a pluralidade social e cultural da condição humana 
apontando para a necessidade de pensar a complexidade destes contextos, a fim de melhor reconhecer as alteridades culturais e sociais como uma das tarefas de desconstrução simbólica da cultura,

$\mathrm{Na}$ descontrução da subjetividade do self moderno, "o único fundamento seguro num mundo onde tudo o mais se tornou sujeito à dúvida radical" (RIEGER, 2009, p. 43), Rieger também usa o aporte lacaniano para "mapear e especificar" mecanismos de cegueira, a partir da noção de "real" do psicanalista francês, e a verdadeira posição de "autoridade", como aquilo que integra o real no simbólico, a fim de precisar melhor os processos de mudança na teologia, que não se reduzem à mudanças em "leis e processos", mas também mudanças no imaginário, que deslegitimem a ideologia do poder como falsa consciência que se pretende apresentar como autoridade. Rieger aponta para a relação ternária da linguagem, sujeito [self] e o outro, no qual a linguagem como fenômeno coletivo pode estar representada no tripé: 1) texto [Escrituras], em que a linguagem invoca um discipulado, enquanto capacidade de transformar leitores, 2) o sujeito [eclesial] e 3) o outro [pobres], como relação que permite a manifestação do real, e assim pode corrigir as fantasias da igreja ideal, pois só um self descentrado e autoridade redistribuída pode escapar de uma psicose social. Do mesmo modo, as transações políticas e econômicas não podem ser libertadas sem ouvir o outro, e o discernimento do mais profundo da escuta implica não somente a experiência pessoal (self), e os textos sagrados, mas sobretudo os outros. O sujeito que ousa encarar o outro e o texto pode ajudar, o retorno ao Outro divino que deve se unir no retorno aos outros humanos. Nesse encontro, o Outro da linguagem pode levar a produzir um novo processo de subjetivação enquanto constituição da "vida interior", além da fixação e do autocentramento preso na luta imaginária com seu outro, mas uma cultura solidária e aberta a acolher a alteridade, especialmente dos que mais precisam (RIEGER, 2009, p. 31-75).

Nessa acepção, o romance saramaguiano não somente corrobora para a mudança de um imaginário cultural, na medida em que a "ficção saramaguiana advoga uma compreensão da realidade sempre mediada e apreendida por intermédio da linguagem", mas também de um imaginário religioso, na medida em que a tessitura de seus romances "contém uma «teologia» crítica que nasce de um locus ateísta”, como afirma o teólogo brasileiro Márcio Cappelli, de haver uma "teologia ficcional" no Nobel de Literatura português (CAPPELLI, 2019, p. 209). 
Sendo o romance um intérprete da vida e a teologia ficcional saramaguiana "uma problematização da fé no reuso dos textos bíblicos" (CAPPELLI, 2019, p. 131), no último capítulo do Ensaio sobre a cegueira antecedendo a recuperação da visão, e, portanto, ainda constatando as cegueiras presentes na cidade, a pequena comunidade guiada pela mulher avista uma Igreja em que os santos todos estão com os olhos vendados, a começar de um "homem pregado na cruz com uma venda branca a taparlhes os olhos, e ao lado, uma mulher com o coração trespassado por sete espadas, e os olhos também tapados por uma venda branca". As demais imagens [estátuas e quadros] todas com os olhos vendados ou com uma "grossa pincelada de tinta branca", como em

uma mulher a ensinar a filha a ler, e as duas tinham os olhos tapados, e um homem com um livro aberto onde se sentava um menino pequeno, e os dois tinham os olhos tapados, um velho de barbar compridas, com três chaves na mão, e tinha os olhos tapados, o outro homem com o corpo clavejado de flechas, e tinha os olhos tapados, e uma mulher com uma lanterna acessa, e tinha os olhos tapados, e um homem com feridas nas mãos nos pés e no peito, e tinha os olhos tapados, e outro homem com um leão, e os dois tinham os olhos tapados, e outro homem com uma águia, e os dois tinham os olhos tapados, e outro com uma lança dominando um homem caído, chavelhudo e com pés de bode, e os dois tinham os olhos tapados, e outro homem com uma balança, e tinha os olhos tapados, e um velho calvo segurando um lírio branco, e tinha os olhos tapados, e outro velho apoiado a uma espada desembainhada, e tinha os olhos tapados, e uma mulher com uma pomba, e as duas tinham os olhos tapados, e um homem com dois corvos e os três tinham os olhos tapados, só havia uma mulher que não tinha os olhos tapados porque já os levava arrancados num bandeja de prata (SARAMAGO, 1995, p. 301).

A narrativa vai aludindo a santos emblemáticos da Igreja Católica, desde seu fundador Jesus Cristo, passando por Maria e mais à frente citando José e, portanto, toda a Sagrada Família, atingindo seus pilares como Pedro e Paulo, os Evangelistas, grandes mártires como Santa Cecília, São Sebastião, taumaturgos como São Francisco e São Vicente, o dos "corvos", mártir do século III em Valência durante as perseguições de Diocleciano, e que por mandato de Dom Afonso Henriques, trouxe suas relíquias à cidade. O que há de comum entre eles, é que todos "tinham os olhos tapados". Com essa crítica parece que Saramago coloca o Cristianismo em geral e a Igreja Católica em particular, na mesma condição de cegueira que as demais instituições, e que 
seu modo de ver a sociedade também é insuficiente para a descaracterização que todos sofrem nesse "não-lugar" de uma sociedade transitória, desde seus valores até seus programas institucionais. As imagens, evocando lacanianmente a tradicional linguagem do Outro que Riger vincula à imagem divina, são problematizadas desde um lugar comum, e não de eleitos, que é a condição comum de ser infectado, pois as imagens estão tapadas, porque elas "vêem com os olhos que as vêem", e portanto, "misericordiosos ou sofredores olhares não contemplavam mais que a própria cegueira" (SARAMAGO, 1995, p. 302-303).

Entender o ateísmo de Saramago como um locus theologicus implica em reconhecer que a religião é um fenômeno muito mais complexo que o reducionismo iluminista intentava empreender, para extrair do próprio fenômeno religioso, sua força cultural, no caso saramaguiano, especificamente a capacidade cristianismo de comportar em seu próprio seio, sua capacidade de desconstrução do "fator Deus" (CAPPELLI, 2019, p. 175), e suas imagens que evocam uma segurança consoladora inibidora da responsabilidade ética, na qual a "a figura de Jesus" contrasta e evoca a ressignificação do próprio cristianismo.

O evento pandêmico, visto sob a ótica da metáfora da cegueira saramaguiana pode ser potencialmente desconstrutor das imagens de Deus no Ocidente que serviram e servem para promover falsos messianismos políticos, e ao mesmo tempo redescobrir na apreensão poética do próprio signo teológico da crucificação de um Deus todo poderoso, o chamado a uma comunidade unida de alteridades em torno de um dever ético de cuidado, especialmente, com aqueles que mais sofrem, e alvo maior da cegueira da sociedade contemporânea. É a violência simbólica da cegueira que se desvela no momento apocalíptico e põe em cena as causas de tal cegueira. A imagem da cegueira visa colocar em questão as certezas negacionistas para se apropriar do ultrapassa a condição humana, não para destruir, mas para reconectar a comunidade humana.

Essa mesma característica de cegueira e desvelamento o Papa Francisco parece assumir em sua Oração em Tempo de Epidemia em que inicia com a cena do Evangelho de Marcos de Jesus com seus discípulos "ao entardecer” (Marcos 4,35), no cair da noite quando a clareza das coisas já não é mais possível e evoca assim o entardecer e a noite que cai com este momento de pandemia no qual as certezas parecem ser insuficientes e se esvaem. Une assim, a angústia do contemporâneo a angústia dos discípulos 
que em meio a tempestade gritam a seu Mestre que tranquilo dormia: "vamos perecer" (cf. 4,38).

Vencer as tempestades do mar é uma narrativa clássica da Antiguidade. $\mathrm{Na}$ Odisseia, Ulisses leva 20 anos para retornar à Ítaca, enfrentando Posídon no mar. Mas há uma evolução na teologia homérica da Ilíada para a Odisseia, pois na primeira tudo o que acontecia na vida dos mortais era tido como vontade dos deuses, já na Odisseia a única mediação entre Ulisses e Zeus é Athenas. Há uma busca de amizade com a deusa da sabedoria (filo-sophia) que conduz o herói grego à aprendizagens fundamentais que ajuda a cumprir seu périplo. As tempestades do Evangelho evocam não tanto o maravilhoso, mas que sabedoria se faz necessária para não perecer. E por isso, Jesus após acalmar a tempestade indaga: "Porque sois tão medrosos? Ainda não tendes fé?" (4, 40).

A fé do Evangelho não é só uma crença, mas, tal qual as literaturas da Antiguidade, é narrada como oferta de um caminho de vida e uma busca de sabedoria que implica olhar o mundo desde a perspectiva de Jesus, no Evangelho. Este aponta para uma disposição à fraternidade e uma constante mudança de mentalidade (metanoia) de se despir de certezas que cegam para criativamente co-criar a humanidade. Francisco, assim, indica algumas causas de cegueira contemporâneas face ao espanto de se evidenciar a insuficiência de um modo de pensar este momento:

Nesta tarde, Senhor, a tua Palavra atinge e toca-nos a todos. Neste nosso mundo, que Tu amas mais do que nós, avançamos a toda velocidade, sentindonos em tudo fortes e capazes. Na nossa avidez de lucro, deixamo-nos absorver pelas coisas e transtornar pela pressa. Não nos detivemos perante os teus apelos, não despertamos face a guerras e injustiças planetárias, não ouvimos o grito dos pobres e do nosso planeta gravemente enfermo. Avançamos, destemidos, pensando que continuaríamos sempre saudáveis num mundo doente. Agora nós, sentindo-nos em mar agitado, imploramos-Te: «Acorda, Senhor!» (Francisco, Momento Extraordinário de Oração em Tempo De Epidemia, 27 de Março de 2020)

\section{Conclusão}

A Pandemia do COVID19 se impõe como evento que tanto se torna um desafio às Ciências da Saúde, e especialmente para o desenvolvimento de vacinas, mas também um desafio social e acadêmico na medida em que desvela as fragilidades sociais e miopias culturais de uma época. Tais desafios apesar de serem muito próximos ao ambiente das Grandes Guerras, especialmente com a recessão econômica que se instala com esses episódios 
históricos, podem ser analisados em suas proximidades e diferenças. As proximidades entre os conflitos bélicos do Século XX e a pandemia do Século XXI incidem sobre os mesmos problemas que são agravados com a escassez econômica e a retração do enriquecimento das nações, nomeadamente a dificuldade de integrar as diferenças culturais que acabam por serem culpabilizadas pela situação de disputa pelos escassos postos de trabalho e inchaço de estruturas do Estado de bem-estar social. Repete-se um fantasma ainda não exorcizado que alimenta o medo entre as povos e nações.

O esforço de unidade cultura se impõe como projeto de sociedade, e está é uma tarefa que tem sido um exercício constante desde o século passado até agora, e que a relativamente pequena percentagem de grupos que apoiam personagens políticos com discursos anacrônicos e com reminiscências de narrativas de ódio (não mais que 30\% em média no cenário internacional) revelam um relativo sucesso cultural de mudança de mentalidade. No entanto, esse baixo percentual de 30\% é capaz de conseguir vitórias eleitorais pela falta de unidade entre os demais grupos que se apresentam com consciência crítica e histórica. A falta de um imaginário que atenda a sangria da fratura simbólica que se desloca de seu nicho natural do âmbito político e transborda para o nível sócio-cultural e promovendo intolerância, divisão social e segregação cultural. Tais formas de divisão estão na origem do fenômeno da cegueira que demanda processos que promovam uma diversidade reconciliada e perspectivas interculturais, para que pessoas diferentes com problemas comuns encontrem soluções cooperativas. A diversidade democrática não subsiste à falta de uma unidade cultural em que permite entender o papel da crítica e da diversidade em elucidar pontos cegos de percepção. O diferente é fundamental para que haja lucidez e efetiva interação com a realidade. Os mecanismos que invisibilizam a alteridade, e consequentemente dividem uma nação, não raro estão alinhados a estratégias de poder que visam criar culpados a serem eliminados, uma receita dosada com crescentes doses de violência.

O evento pandêmico da cegueira ficcional em Saramago, assim como a real em Francisco, indicam um momento sob o signo do Apocalipse, mas não no sentido mais vulgar e cinematográfico da narrativa bíblica que aponta para o fim do mundo. Mas sim dentro da perspectiva da literatura apocalíptica com características de seu gênero literário que visa "desvelar" a realidade e indica assim o fim de um mundo, aquele que já não é mais possível viver com o modo de se ver as coisas, pensar os problemas e imaginar o futuro. Tal desvelamento é um convite a uma mudança de 
mentalidade, em que mudando como se pensa, muda-se como se vive, pois "não há cegos, mas cegueiras".

Nesse sentido o novo COVID19 instala uma situação apocalíptica que acelera a necessidade de mudança de um modo de vida, e consequentemente da criação de espaços comuns por meio do diálogo social que visem sanar as fraturas de divisão cultural, pois diante das cegueiras, só a voz e o ouvido tem alguma utilidade, diz o romancista, a fim de a diversidade não seja vista como ameaça, mas um elemento constitutivo para a construção do bem comum. Vale repetir o conselho da própria literatura bíblica apocalíptica, face aos eventos desveladores da realidade, em que é necessário ter "um colírio para ungir os olhos, de modo que possas ver claro" (Apocalipse 3,18). E tal clareza implica o reconhecimento da comum dignidade que precisa ser traduzida em modos de operacionalizar um estilo de vida com consciência de habitar a mesma Casa que é comum a toda diversidade. O evento pandemia, na medida em que instala uma crise social, política, econômica e cultural por desvelar as fragilidades da sociedade contemporânea inaugura um tempo de busca de compreensão do modo de ser da própria sociedade, que implica também a mudança de mentalidade religiosa.

\section{Referências}

ARAÚJO, A. F.; BAPTISTA, F. P. Variações sobre o imaginário: Domínios, Teorizações e Práticas Hermenêuticas. Col. Pensamento e Filosofia. Lisboa: Instituto Piaget, 2003.

AUDIER, Serge. La Pensee Anti-68: Essai sur les origines d'une restauratioon intelectuelle. Paris : La Decouverte, 2008.

BAUMAN, Zygmunt. Modernidade e Holocausto. Trad.: Marcus Penchel. Rio de Janeiro: Zahar, 1989.

BAUMAN, Zygmunt; DONSKINS, Leonidas. Cegueira Moral: A perda da sensibilidade na Modernidade Líquida. Zahar Editores, 2013.

CAPPELLI, Marcio. A Teologia Ficcional de José Saramago: Aproximações entre Romance e Reflexão Teológica. Lisboa: Imprensa Nacional, 2019.

DUNKER, C.I.L. Tempo e Linguagem na Psicose da Criança. Tese de Doutorado. Instituto de Psicologia da Universidade de São Paulo, 1996.

FABRE, Pierre Antoine. Une érudition critique : Michel de Certeau vers 1968. Fabula - La Recherche en Literature. Les colloques, Revisiter l'œuvre de M. de Certeau URL: <http:// www.fabula.org/colloques/document4655.php>. Acesso em : 06. Jun. 2017.

FELIPPI, M. C. P. O Espírito como Herança: As origens do sujeito contemporâneo na obra de Hegel. Col. Filosofia, 71. Porto Alegre: EDIPUCRS, 1998. 
FRANCISCO. Momento Extraordinário de Oração em Tempo De Epidemia ["Urbi et Orbi’”. Vaticano: Libreria Editrice Vaticana; 2020.

FRANCO, Maria Estela Dal Pai. O reinventor de identidades - Entrevista com José Saramago ao Jornal da Universidade- UFRGS (Maio de 1999) In SULIANI, Antônio (org.). Etnias \& Carisma. Porto Alegre: EDIPUCRS, 2011, p. 730-751.

JAMESON. Fredric. O inconsciente político: a narrativa como ato socialmente simbólico. São Paulo: Ática, 1992.

LACAN, J. (1932). De la Psycose paranoïque dans ses rapports avec la personalité. Paris: Seuil, 1975.

LACAN, J. (1932). De la Psycose paranoïque dans ses rapports avec la personalité. Paris: Seuil, 1975.

LACAN, J. (1953-54). Seminário 1: os escritos técnicos de Freud. Rio de Janeiro: Jorge Zahar, 1986.

LACAN, J. (1955-1956). O Seminário - livro 3: As psicoses. Rio de Janeiro: Jorge Zahar Editor, 1995.

LACAN, J. (1956). Écrits. Paris: Seuil, 1966.

LACAN, J. (1957-58). O Seminário. Livro 5: As formações do inconsciente. Rio de Janeiro: Jorge Zahar Editor, 1999.

LACAN, J. (1958-59). O Seminário. Livro 6: O desejo e sua interpretação. Publicação não comercial. Circulação interna da Associação Psicanalítica de Porto Alegre. 2002.

LACAN, J. (1974). Outros Escritos. Rio de Janeiro: Jorge Zahar Editor, 2003.

LACAN, J. Hiatus Irrationalis In Revue Le phare de Neuilly, 1933.

LEBRET, L.-J. Découverte du bein commun: Mystique d'un monde nouveau. Édition Complete. Paris: Éditions Économie et humanisme;1947.

LÉVY, P. As tecnologias da inteligência: o futuro do pensamento na era da informática. São Paulo: Editora 34, 2011.

MEYERSON, E. (1908). Identité et réalité. Paris, Librarie Philosophique J.Vrin, 1951.

MORIN, Edgar (1990). Introdução ao Pensamento Complexo. 5. ed. Lisboa: Instituto Piaget, 2008.

PRADO JR., B. Presença e Campo Transcendental. São Paulo: EDUSP, 1988.

RIEGER, Jorg. Lembrar-se dos pobres: O desafio da teologia no século XXI. São Paulo: Edições Loyola, 2009.

RTP Notícias - Cultura: Saramago diz que é preciso rectificar a situação dos "excluídos" na Europa. Reportagem de 12 nov. 2005. URL: <http://www.rtp.pt/noticias/cultura> Acesso em: 10. out. 2018.

SARAMAGO, José. (1995). Ensaio sobre a Cegueira. Companhia das Letras; 2008. 
SAVATER, Amador Fernández. Michel Foucault: uma nova imaginação política. IHU, 09 jun. 2015. URL: http://www.ihu.unisinos.br/noticias/543288-michel-foucault-uma-novaimaginacao-politica. Acesso em 22. Out. 2018.

WELTER, Roseane. Ética e Subjetividade: Análise da estrutura subjetiva da vida ética segunda Lima Vaz. Cadernos IHU, Ano XIII, n 52. São Leopoldo: Instituto Humanitas Unisinos 2015.

ŽIŽEK, S. Alguém disse totalitarismo? Cinco intervenções no mau (uso) de uma noção. Rio de Janeiro: Editora Boitempo, 2013 (Edição digital)

ŽIŽEK, S. Em defesa das causas perdidas. Rio de Janeiro: Editora Boitempo, 2011.

Submetido em: 16-9-2020

Aceito em: 27-11-2020 